ARTICLE

DOI: $10.1038 / s 41467-018-05755-8$

\title{
Confined small-sized cobalt catalysts stimulate carbon-chain growth reversely by modifying ASF law of Fischer-Tropsch synthesis
}

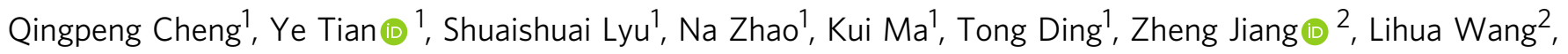
Jing Zhang ${ }^{3}$, Lirong Zheng ${ }^{3}$, Fei Gao ${ }^{4}$, Lin Dong ${ }^{4}$, Noritatsu Tsubaki (i) ${ }^{5}$ \& Xingang Li (iD ${ }^{1}$

Fischer-Tropsch synthesis (FTS) is a promising technology to convert syngas derived from non-petroleum-based resources to valuable chemicals or fuels. Selectively producing target products will bring great economic benefits, but unfortunately it is theoretically limited by Anderson-Schulz-Flory (ASF) law. Herein, we synthesize size-uniformed cobalt nanocrystals embedded into mesoporous $\mathrm{SiO}_{2}$ supports, which is likely the structure of water-melon seeds inside pulps. We successfully tune the selectivity of products from diesel-range hydrocarbons (66.2\%) to gasoline-range hydrocarbons $(62.4 \%)$ by controlling the crystallite sizes of confined cobalt from 7.2 to $11.4 \mathrm{~nm}$, and modify the ASF law. Generally, larger Co crystallites increase carbon-chain growth, producing heavier hydrocarbons. But here, we interestingly observe a reverse phenomenon: the uniformly small-sized cobalt crystallites can strongly adsorb active $C^{\star}$ species, and the confined structure will inhibit aggregation of cobalt crystallites and escape of reaction intermediates in FTS, inducing the higher selectivity towards heavier hydrocarbons.

\footnotetext{
${ }^{1}$ Collaborative Innovation Center of Chemical Science and Engineering (Tianjin), Tianjin Key Laboratory of Applied Catalysis Science and Technology, School of Chemical Engineering and Technology, Tianjin University, 300072 Tianjin, China. ${ }^{2}$ Shanghai Synchrotron Radiation Facility, Shanghai Institute of Applied Physics, Chinese Academy of Sciences, 201800 Shanghai, China. ${ }^{3}$ Beijing Synchrotron Radiation Facility, Institute of High Energy Physics, Chinese Academy of Sciences, 100049 Beijing, China. ${ }^{4}$ Jiangsu Key Laboratory of Vehicle Emissions Control, Center of Modern Analysis, Nanjing University, 21009 Nanjing, China. ${ }^{5}$ Department of Applied Chemistry, School of Engineering, University of Toyama, Gofuku 3190, Toyama 930-8555, Japan. These authors contributed equally: Qingpeng Cheng, Ye Tian. Correspondence and requests for materials should be addressed to N.T. (email: tsubaki@eng.u-toyama.ac.jp) or to X.L. (email: xingang_li@tju.edu.cn)
} 
C oncerns over global oil depletion bring urgent demands to find alternative feedstocks to produce important petrochemicals and fuels. Fischer-Tropsch synthesis (FTS) can synthesize clean liquid fuels via catalytic polymerization of syngas $\left(\mathrm{CO} \text { and } \mathrm{H}_{2}\right)^{1-3}$. In order to obtain the high yield of the target product in FTS, it is necessary to control the selectivity of the corresponding fractions. Unfortunately, over conventional FTS catalysts, the selectivity of products follows the Anderson-Schulz-Flory (ASF) law, which is unselective for the target products ${ }^{2}$. For example, the maximum selectivities to $\mathrm{C}_{5}$ $-\mathrm{C}_{11}$ (gasoline-range) and $\mathrm{C}_{10}-\mathrm{C}_{20}$ (diesel-range) hydrocarbons are $\sim 45 \%$ and $\sim 39 \%$, respectively. Conventionally, the FTS products are subjected to further hydro-treatment to improve the selectivity of liquid fuels ${ }^{4}$. The direct production of target-range liquid fuels will be more efficient in energy and economically effective than the multiple-stages process. It is urgent to design high-performance FTS catalysts with a high selectivity to target products $^{4-6}$.

Metallic cobalt, ruthenium, and iron are conventional FTS catalysts. Cobalt-based catalysts have the advantages of the low activity in water gas shift reaction, and the high catalytic activity and stability in $\mathrm{FTS}^{6,7}$. The crystallite sizes of cobalt can dramatically affect the catalytic activity and selectivity for FTS $^{7-11}$. De Jong's group ${ }^{8,9}$ reported a non-classical structure sensitivity for the Co/CNFs catalysts. The turnover frequency (TOF) values of the catalysts continuously increased with the enlarged crystallite sizes of cobalt, and then became constant when the crystallite sizes were larger than $6-8 \mathrm{~nm}$. They also found that the $\mathrm{C}_{5}{ }^{+}$selectivity of the products increased from 51 to $85 \%$, when the crystallite sizes of cobalt increased from 2.6 to $16 \mathrm{~nm}$. Although this view is generally accepted, it is still under debate. Borg et al. ${ }^{10}$ and Holmen's group ${ }^{11}$ reported that the $\mathrm{C}_{5}{ }^{+}$selectivity showed a volcano-like variation via the enlarged sizes of the cobalt crystallites. In their work, the $\mathrm{C}_{5}{ }^{+}$selectivity increased with the enlarged crystallite sizes of cobalt smaller than $\sim 8 \mathrm{~nm}$ and reached the maximum value, and then it dropped with the further enlarged cobalt crystallites over the $\mathrm{Co} / \mathrm{Al}_{2} \mathrm{O}_{3}$ catalysts ${ }^{10,11}$. Nevertheless, Iglesia ${ }^{12}$ claimed that the intrinsic reaction rate, as well as the chain-growth of products, did not depend on the crystallite sizes of cobalt in FTS. Thus, it is important to clarify the function of the crystallite sizes of cobalt on the selectivity of products to rationally design and synthesize highly selective FTS catalysts towards specific products.

Researchers have controlled the crystallite sizes of cobalt by different preparation routes, such as incipient wetness impregnation ${ }^{11,12}$, electrostatic adsorption ${ }^{13}$, and homogeneous deposition-precipitation ${ }^{14}$. In general, cobalt will gradually aggregate with proceeding of FTS reactions, which probably brings conflict results on function of crystallite sizes of cobalt on selectivity of products. Confinement structure of catalysts is one of appropriate strategies to stabilize and immobilize metallic crystallites. Somorjai's group ${ }^{15}$ reported that inorganic silica shells encaged Pt crystallite exhibited high catalytic activities for ethylene hydrogenation and $\mathrm{CO}$ oxidation because of restricting sintering of Pt crystallites at high temperatures. Bao's group ${ }^{3}$ also reported that encapsulation of iron species inside carbon nanotubes could effectively inhibit aggregation of iron crystallites, and enhance selectivities towards heavy hydrocarbons ascribed to inhibition of diffusion of reaction intermediates.

Herein, we synthesize the size-uniformed $\mathrm{Co}_{3} \mathrm{O}_{4}$ nanocrystals, which are then embedded into the mesoporous $\mathrm{SiO}_{2}$ support to avoid aggregation in FTS. Surprisingly, we can successfully tune the selectivity of the FTS products from the diesel fraction (66.2\%) to the gasoline fraction $(62.4 \%)$ by controlling the crystallite sizes from 7.2 to $11.4 \mathrm{~nm}$ of the confined cobalt catalysts. It should be noticed that the small-sized cobalt crystallites with the confined structure interestingly give the large chain growth probability $(\alpha)$ and the high selectivity towards heavy hydrocarbons.

\section{Results}

Catalyst synthesis process and structure. Figure 1a describes the catalyst synthesis process. We synthesized the $\mathrm{Co}_{3} \mathrm{O}_{4}$ nanocrystals using tetradecyltrimethlammonium bromide (TTAB) as the capping agent with a facile hydrothermal process. Varying the hydrothermal duration can control the sizes of the $\mathrm{Co}_{3} \mathrm{O}_{4}$ nanocrystals. Thereafter, we utilized the silica-TTAB layer to wrap the TTAB-capped $\mathrm{Co}_{3} \mathrm{O}_{4}$ nanocrystals through an electrostatic interaction between the cationic (TTAB) and anionic (tetraethyl orthosilicate (TEOS)) species. After calcination of the above powder in air to remove TTAB, we successfully achieved the final catalyst, which was denoted as Cat- $x \mathrm{~h}(x=4,8,12)$, where ' $x$ h' was the hydrothermal synthesis period of the $\mathrm{Co}_{3} \mathrm{O}_{4}$ nanocrystals. Figures $1 \mathrm{~b}, \mathrm{c}$ show the transmission electron microscopy (TEM) images for TTAB-capped $\mathrm{Co}_{3} \mathrm{O}_{4}$ and $\mathrm{Co}_{3} \mathrm{O}_{4}$ TTAB-silica, respectively. The TTAB-capped $\mathrm{Co}_{3} \mathrm{O}_{4}$ nanocrystals in Fig. $1 \mathrm{~b}$ and Supplementary Fig. 1 mainly exist in cubic shape and exhibit a uniform size distribution. The results of TEM (Supplementary Fig. 1) and X-ray diffraction (XRD; Supplementary Fig. 2) of the TTAB-capped $\mathrm{Co}_{3} \mathrm{O}_{4}$ nanocrystals reveal that the sizes of the $\mathrm{Co}_{3} \mathrm{O}_{4}$ nanocrystals increase with the prolonged hydrothermal duration. Figure 1c shows the assembled structure of the $\mathrm{Co}_{3} \mathrm{O}_{4}$-TTAB-silica nanocomposites.

After calcination of the $\mathrm{Co}_{3} \mathrm{O}_{4}$-TTAB-silica nanocomposites, the cubic $\mathrm{Co}_{3} \mathrm{O}_{4}$ nanocrystals changed to the spheric shape (Fig. 1d). For the Cat- $x$ h catalysts (Table 1, Supplementary Fig. 3 and Supplementary Table 1), capping of silica did not change the original sizes of the $\mathrm{Co}_{3} \mathrm{O}_{4}$ nanocrystals. Table 1 gives the textural properties of these catalysts evaluated by $\mathrm{N}_{2}$ physisorption. The results of nitrogen adsorption-desorption isotherms reveal that the Cat- $x$ h catalysts (Supplementary Fig. 4) are mesoporous ${ }^{15}$ with the surface areas of $\sim 320 \mathrm{~m}^{2} \mathrm{~g}^{-1}$. Summarily, our Cat- $x \mathrm{~h}$ catalysts show a water-melon-like structure, where water-melon seeds (cobalt nanocrystals) are embedded inside pulps (silica bulk matrix).

Figure 2a shows the XRD patterns of the reduced Cat- $x \mathrm{~h}$ catalysts. We observed two types of the metallic cobalt phases including the cubic phase with the strong diffraction peaks (facecentered cubic (FCC); JCPDS 15-0806) and the hexagonal phase with the weak diffraction peaks (hexagonal close-packed (HCP); JCPDS 05-0727) ${ }^{16}$. The crystallite sizes of metallic cobalt have a similar tendency with the above mentioned $\mathrm{Co}_{3} \mathrm{O}_{4}$ nanocrystals. Figure $2 \mathrm{~b}$ shows the $\mathrm{Co} \mathrm{K}$-edge radial distribution functions (RDFs) of the reduced Cat- $x$ h catalysts and the standard Co-foil. The RDFs of the reduced Cat- $x$ h catalysts display the remarkably lower peak amplitudes than that of the Co foil, indicating the formers' lower coordination numbers. Supplementary Table 2 gives the simulated data determined from Fig. 2b. The cobalt species in the reduced Cat- $x \mathrm{~h}$ catalysts exist in the metallic state. The Co-Co coordination numbers of the reduced Cat- $4 \mathrm{~h}$, Cat- $8 \mathrm{~h}$, and Cat-12h catalysts are $7.3,8.1$, and 9.3, respectively, which are much smaller than that of the Co foil (12.0). These findings suggest that the dispersion of the cobalt species follows the sequence of Cat $-4 \mathrm{~h}>\mathrm{Cat}-8 \mathrm{~h}>\mathrm{Cat}-12 \mathrm{~h}$, as well as an inverse sequence of the crystallite sizes.

Embedment of $\mathrm{Co}_{3} \mathrm{O}_{4}$ nanocrystals. Table 1 gives the metal dispersion $(D)$ and mean particle sizes $\left(d\left(\mathrm{Co}^{0}\right)_{\mathrm{H}}\right)$ of cobalt determined from the $\mathrm{H}_{2}$-chemisorption. In Table 1, the Cat-IM catalyst prepared by a conventional incipient-wetness impregnation method (IM) displays a low metal dispersion (7.8\%) with a $d$ 
$\mathbf{a}$
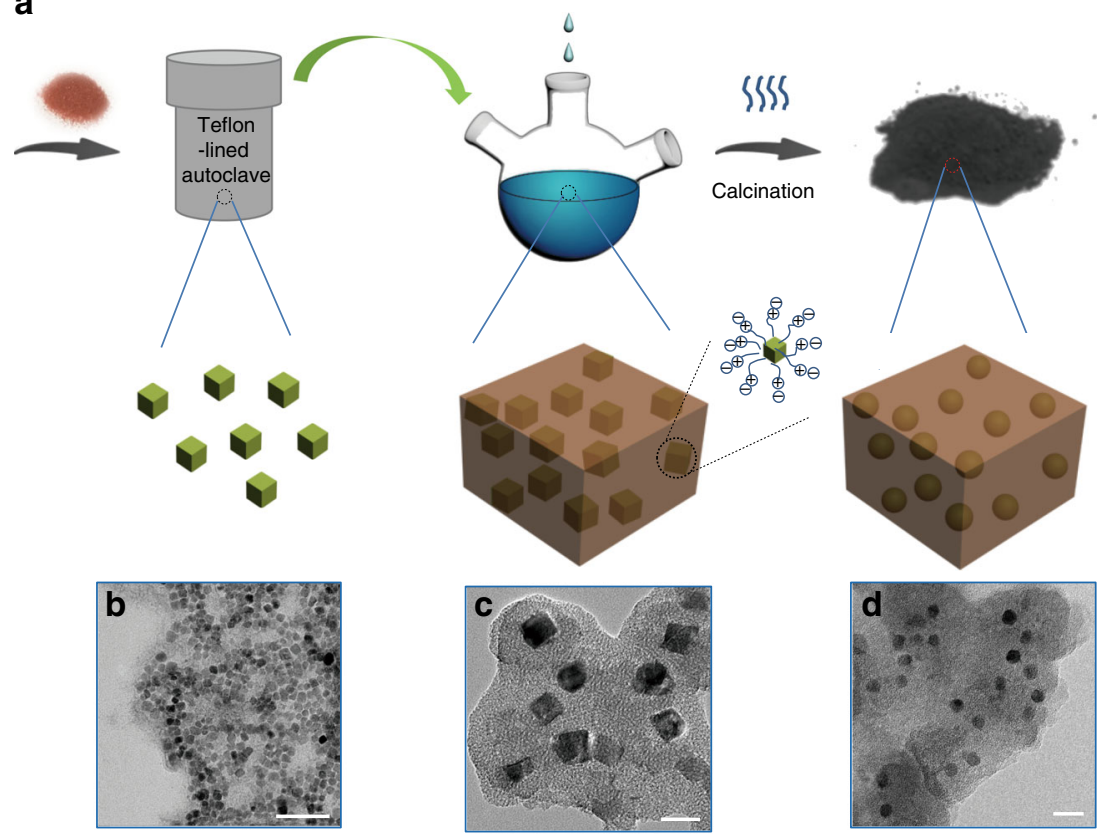

$=$ cubic $\mathrm{Co}_{3} \mathrm{O}_{4}$ nanocrystals
$=\mathrm{CO}_{3} \mathrm{O}_{4}$ nanocrystals

$\oplus=\mathrm{TTAB}$

$\Delta \theta=$ TEOS

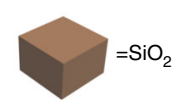

Fig. 1 Synthesis of the Cat-xh catalysts. a Schematic illustration of the synthesis of the $\mathrm{Co}_{3} \mathrm{O}_{4}$ nanocrystals with the narrow size distribution and the preparation of the $\mathrm{Cat}-x \mathrm{~h}$ catalysts with the uniform size distribution. b-d TEM images of the materials containing $\mathrm{Co}_{3} \mathrm{O}_{4}$ hydrothermal-synthesized for $8 \mathrm{~h}$. b TTAB-capped $\mathrm{Co}_{3} \mathrm{O}_{4}$ nanocrystals. c $\mathrm{Co}_{3} \mathrm{O}_{4}-\mathrm{TTAB}$-silica nanocomposite. d Cat-8h. Scale bars: b $50 \mathrm{~nm}$; c $10 \mathrm{~nm}$; d $20 \mathrm{~nm}$

Table 1 Chemical and physical properties of the catalysts

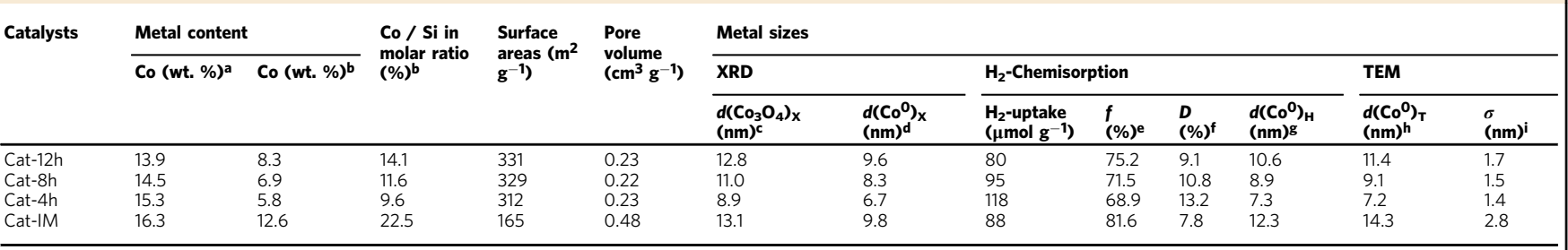

aFrom ICP-MS

bFrom XPS

CCalculated using the Scherrer's equation. The suffix $X$ denoted $X R D$

dCalculated applying the molar volume correction: $d\left(\mathrm{CO}^{0}\right)_{X}=\frac{3}{4} d\left(\mathrm{CO}_{3} \mathrm{O}_{4}\right)_{X}$. The suffix $X$ denoted XRD

eReduction degree

fMetal dispersion

gThe suffix $\mathrm{H}$ standing for $\mathrm{H}_{2}$-chemisorption

hFrom TEM images. The suffix T standing for TEM

iStandard deviation for the crystallite size distribution

$\left(\mathrm{Co}^{0}\right)_{\mathrm{H}}$ of $12.3 \mathrm{~nm}$. Nevertheless, its $d\left(\mathrm{Co}^{0}\right)_{\mathrm{H}}$ is substantially larger than the value $\left(d\left(\mathrm{Co}^{0}\right)_{\mathrm{X}}=9.8 \mathrm{~nm}\right)$ estimated from the XRD characterization. It suggests that migration and growth of the metallic cobalt take place upon $\mathrm{H}_{2}$ reduction of the Cat-IM catalyst, owing to a weak interaction between the cobalt and the support. Nevertheless, the $d\left(\mathrm{Co}^{0}\right)_{\mathrm{H}}$ values are similar to those derived from the XRD characterization for the reduced Cat- $x \mathrm{~h}$ catalysts.

Figure 3 shows the TEM images and the corresponding distributions of the crystallite sizes of cobalt of the reduced catalysts. In Fig. 3, the metallic cobalt crystallites are homogeneously dispersed on the reduced Cat- $x \mathrm{~h}$ catalysts with a narrow size distribution. Especially, they are embedded inside the mesoporous silica support in a water-melon-like structure
(Fig. 3b, e, h). The embedment strategy has enormous advantage in controlling the size of cobalt than the traditional impregnation method (Supplementary Figs. 5, 6 and Fig. 3g-1). It indicates that the embedded spatial confinement of the Cat-xh catalysts can effectively prevent the metal migration and growth. It well explains the little difference between $d\left(\mathrm{Co}^{0}\right)_{\mathrm{H}}$ and $d\left(\mathrm{Co}^{0}\right)_{\mathrm{X}}$ for the confined Cat-xh catalysts in Table 1.

Figure 4a shows the temperature-programmed reduction of $\mathrm{H}_{2}$ $\left(\mathrm{H}_{2}\right.$-TPR) profiles of the catalysts. The Peak I and II below $400{ }^{\circ} \mathrm{C}$ can be assigned to the reduction of the surface and the bulk of $\mathrm{Co}_{3} \mathrm{O}_{4}$, respectively ${ }^{17}$. The Peak III may be ascribed to the reduction of the cobalt species deeply embedded into silica because of the diffusion limitation of $\mathrm{H}_{2}{ }^{6}$, and the Peak IV located above $600{ }^{\circ} \mathrm{C}$ can be assigned to the reduction of cobalt species 

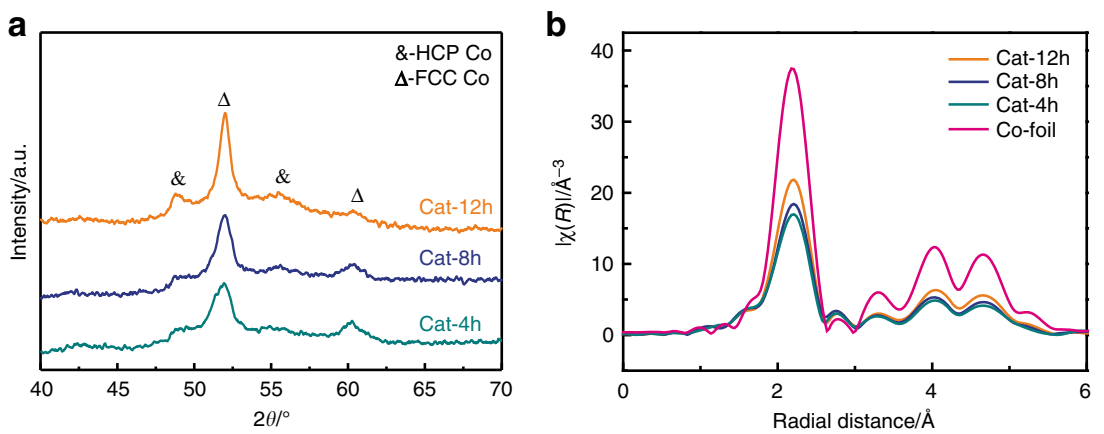

Fig. 2 Structure of the reduced catalysts. a XRD patterns of the reduced Cat-xh catalysts. The crystallite sizes of metallic cobalt in the reduced catalysts are estimated to be $10.2,8.2,6.5 \mathrm{~nm}$ based on the Scherrer's equation. $\mathbf{b}$ RDFs spectra of the reduced catalysts and the reference Co foil
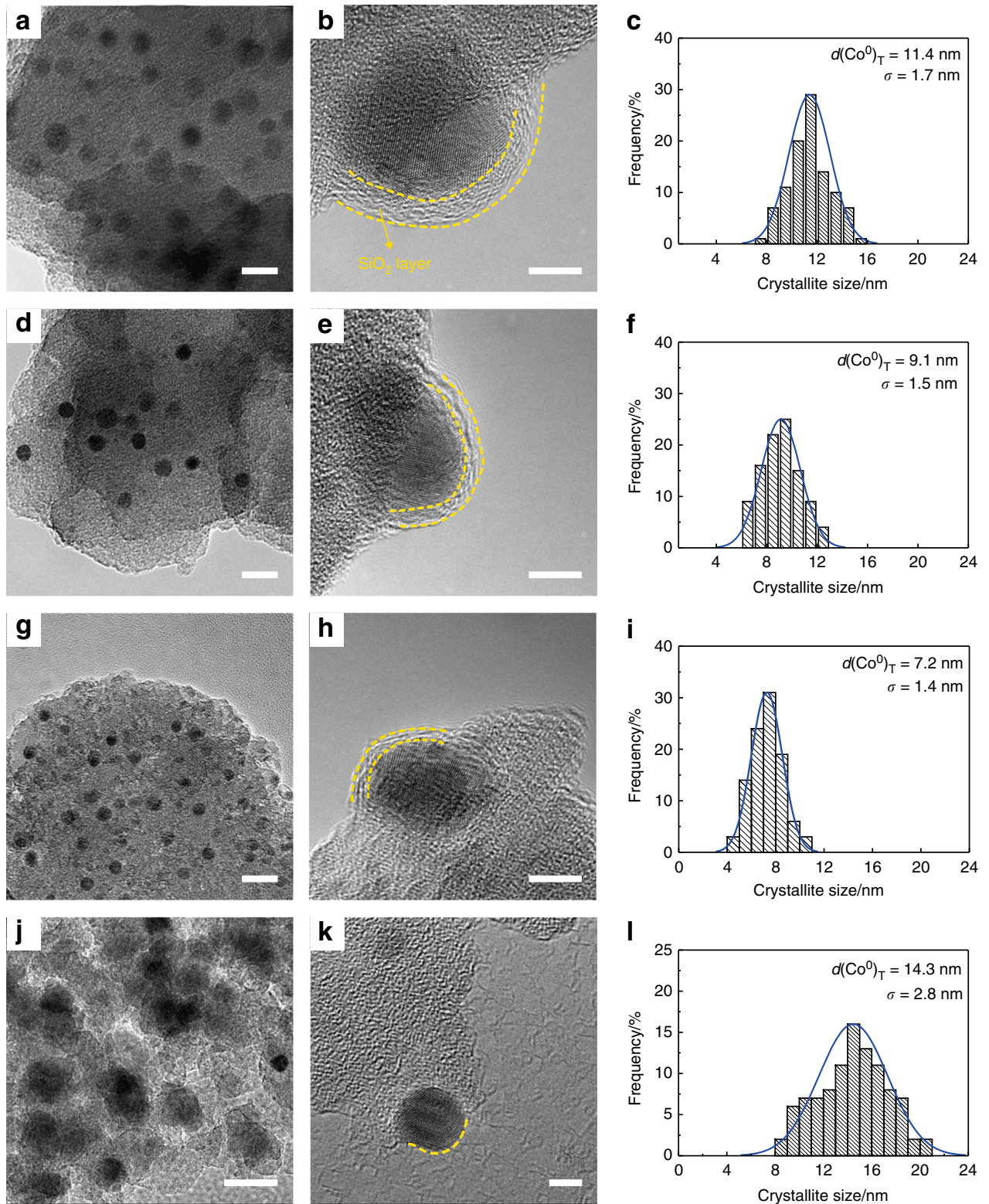

Fig. 3 TEM images and corresponding crystallite size distributions of the reduced catalysts. $\mathbf{a}, \mathbf{d}, \mathbf{g}, \mathbf{j}$ TEM and $\mathbf{b}, \mathbf{e}, \mathbf{h}, \mathbf{k}$ HRTEM images of the reduced Catxh catalysts. $\mathbf{c}, \mathbf{f}, \mathbf{i}, \mathbf{I}$ Corresponding crystallite size distributions of the reduced catalysts. $\mathbf{a}, \mathbf{b}, \mathbf{c}$ Cat- $12 \mathrm{~h}, \mathbf{d}, \mathbf{e}, \mathbf{f}$ Cat-8h, $\mathbf{g}, \mathbf{h}, \mathbf{i}$ Cat-4h, and $\mathbf{j}, \mathbf{k}, \mathbf{I}$ Cat-IM. Scale bars: a, d, $\mathbf{g}, \mathbf{j} 20 \mathrm{~nm} ; \mathbf{b}, \mathbf{e}, \mathbf{h}, \mathbf{k} 5 \mathrm{~nm}$ 

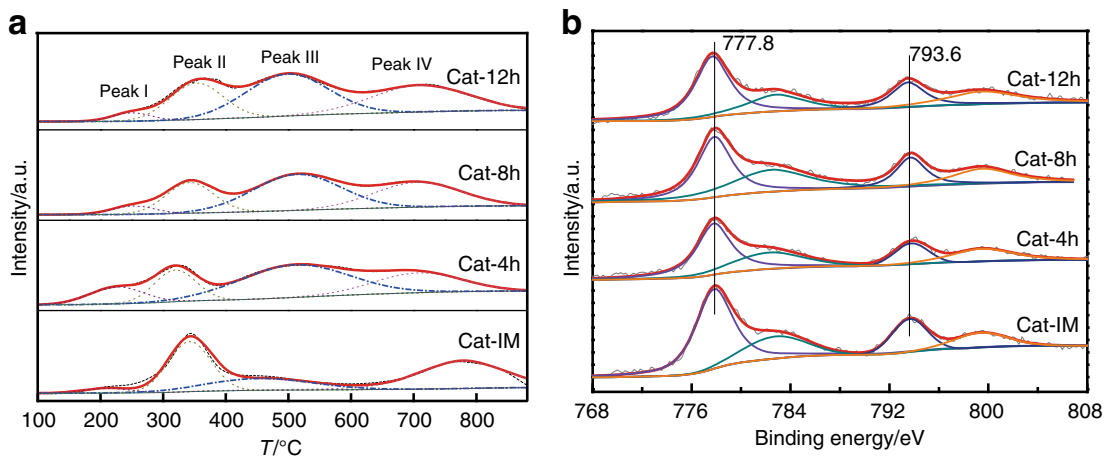

Fig. 4 Embedment of Co species. a $\mathrm{H}_{2}$-TPR profiles of the catalysts. $\mathbf{b}$ In situ XPS spectra of the catalysts at Co $2 p$ core levels

Table 2 FTS activity data of the catalysts

\begin{tabular}{|c|c|c|c|c|c|c|c|c|}
\hline \multirow[t]{2}{*}{ Catalysts } & \multirow[t]{2}{*}{ CO Conversion (\%) } & \multirow[t]{2}{*}{ TOF $\left(s^{-1}\right)$} & \multicolumn{6}{|c|}{ Selectivity (\%) } \\
\hline & & & $\mathrm{CH}_{4}$ & $C_{2}-C_{4}$ & $\mathbf{C}_{5}^{+}$ & $C_{5}-C_{11}$ & $C_{10}-C_{20}$ & $\mathbf{C}_{\mathbf{2 1}}^{+}$ \\
\hline Cat-12h & 80.6 & 0.064 & 8.7 & 11.3 & 80.0 & 62.4 & 23.7 & 5.7 \\
\hline Cat-8h & 78.2 & 0.049 & 10.4 & 14.7 & 74.9 & 42.4 & 39.3 & 6.4 \\
\hline Cat-4h & 77.0 & 0.039 & 8.0 & 7.8 & 84.2 & 15.6 & 66.2 & 7.8 \\
\hline Cat-IM & 84.0 & 0.065 & 18.0 & 14.7 & 67.3 & 43.5 & 29.7 & 5.1 \\
\hline
\end{tabular}

Note: Reaction condition: $P=2 \mathrm{MPa}, T=220^{\circ} \mathrm{C}, \mathrm{W} / \mathrm{F}=5.1 \mathrm{~g}_{\text {cat }} \mathrm{h}$ mol$-1, \mathrm{CO} / \mathrm{H}_{2}=1 / 2$

strongly interacted with silica ${ }^{7,18,19}$. In Supplementary Table 3, the areas of the Peak III for the Cat- $x$ h catalysts follow the sequence of Cat $-4 \mathrm{~h}>\mathrm{Cat}-8 \mathrm{~h}>\mathrm{Cat}-12 \mathrm{~h}$, and are much larger than that of the Cat-IM catalyst. It indicates that compared with the Cat-IM catalyst, more cobalt species are deeply embedded into silica on the Cat- $x$ h catalysts, further confirming the embedment structure of the Cat- $x$ h catalysts.

In addition, we evaluated the composition of the surface atoms of the catalysts using in situ X-ray photoelectron spectroscopy (XPS; Fig. 4b). The values of the $\mathrm{Co} / \mathrm{Si}$ atomic ratio of the Cat- $x \mathrm{~h}$ catalysts increase from 9.6 to $14.1 \%$ with the increase of the crystallite sizes of metallic cobalt (Table 1), but all of them are much lower than that of the Cat-IM (22.5\%). In general, the smaller crystallite size of cobalt on the catalysts will expose the more superficial cobalt species. But, the results of in situ XPS break the rule, resulting from the embedment of cobalt into silica for the Cat- $x$ h catalysts. Moreover, despite of the high loading (about $15 \mathrm{wt} . \%$ ) and the excellent dispersion of cobalt, only $5.8-8.3$ wt.\% of cobalt locates on the surface of the Cat- $x \mathrm{~h}$ catalysts, further certifying the embedment of the cobalt species into the silica support therein.

Catalytic behaviors in FTS. We evaluated the catalytic activity and selectivity of the Cat- $x$ h catalysts in FTS, and Table 2 gives the related data. In Table 2, with the enlargement of the metallic cobalt crystallites the CO conversion slightly increases from 77.0 to $80.6 \%$, meanwhile the TOF value remarkably increases from $3.9 \times 10^{-2}$ to $6.4 \times 10^{-2} \mathrm{~s}^{-1}$.

Table 2 and Fig. 5 a also provide the FTS product distributions over the Cat- $x$ h catalysts. It should be noticed that generally, the references only reported the $\mathrm{C}_{5}{ }^{+}$selectivity ${ }^{7-12}$. But for our Cat$x$ h catalysts, no obvious tendency towards the $\mathrm{C}_{5}{ }^{+}$selectivity was observed, which varied from $\sim 75$ to $84 \%$. But, very interestingly, the Cat-12h catalyst exhibits a $\mathrm{C}_{5}-\mathrm{C}_{11}$ (gasoline-range) selectivity of $62.4 \%$; the Cat- $8 \mathrm{~h}$ catalyst exhibits a $\mathrm{C}_{5}-\mathrm{C}_{11}$ selectivity of $42.4 \%$ and $\mathrm{C}_{10}-\mathrm{C}_{20}$ (diesel-range) selectivity of $39.3 \%$; and the Cat- $4 \mathrm{~h}$ catalyst exhibits a $\mathrm{C}_{10}-\mathrm{C}_{20}$ selectivity of $66.2 \%$.
Surprisingly, through controlling the crystallite sizes of cobalt and designing of the confined reaction field, we can tune the selectivity of the FTS products from the lower molecular weights, such as $\mathrm{C}_{5}-\mathrm{C}_{11}$, to the higher molecular weights, such as $\mathrm{C}_{10}-\mathrm{C}_{20}$ (Fig. 5a). However, unlike the confined Cat- $x$ h catalysts, the Cat$\mathrm{IM}-x \mathrm{~h}$ catalysts prepared by impregnating as-synthesized $\mathrm{Co}_{3} \mathrm{O}_{4^{-}}$ $x \mathrm{~h}$ precursors over silica supports do not exhibit a narrow product distribution for either gasoline-range or diesel-range hydrocarbons with the size change of the cobalt particles (Supplementary Table 4 and Supplementary Fig. 7). It indicates the important role of the embedment structure of the Cat- $x \mathrm{~h}$ catalysts on the FTS product selectivity. Figure $5 \mathrm{~b}$ and Supplementary Fig. 8 show the $\alpha$ values of the catalysts. The $\alpha$ values of the Cat- $x \mathrm{~h}$ catalysts decrease from 0.85 of the Cat-4h to 0.73 of the Cat- $12 \mathrm{~h}$ with the increase of the crystallite sizes of cobalt. It indicates that the smaller crystallite sizes of the confined cobalt catalyst favor chain growth, resulting in the higher selectivity of heavy hydrocarbons. The results of the repeated experiments on Cat-12h (Supplementary Fig. 9a and Supplementary Table 5) and Cat-4h (Supplementary Fig. 9b and Supplementary Table 6) catalysts prove that our catalysts have good reproducibility.

Generally, textural structures ${ }^{20-22}$, acid properties ${ }^{23-25}$, crystallite sizes of metal species ${ }^{11,26,27}$ and confinement structures ${ }^{3,6,26}$ can affect product distributions in FTS. The textural structures can affect the diffusibility of reactants and products leading to varied activities and selectivities ${ }^{20-22}$. We did not observe an obvious change for the textural structures of the Cat- $x \mathrm{~h}$ catalysts in Table 1. Moreover, we carried out the experiments with the different contact time over the Cat-12h (Fig. 5c) and Cat-4h catalysts (Fig. 5d). With the prolonging of contact time, the Cat$12 \mathrm{~h}$ and Cat-4h catalysts still kept the high selectivity towards $\mathrm{C}_{5}-\mathrm{C}_{11}$ and $\mathrm{C}_{10}-\mathrm{C}_{20}$, respectively. The acid sites on the catalyst may initiate the secondary cracking, isomerization, and aromatization of the primary FTS products ${ }^{23-25}$. There exist some acidic functional groups, such as hydroxyl and carboxyl, on the surface of our silica support, inducing the acidity of the catalysts. The results (Supplementary Fig. 10) of the $\mathrm{NH}_{3}$-temperature 

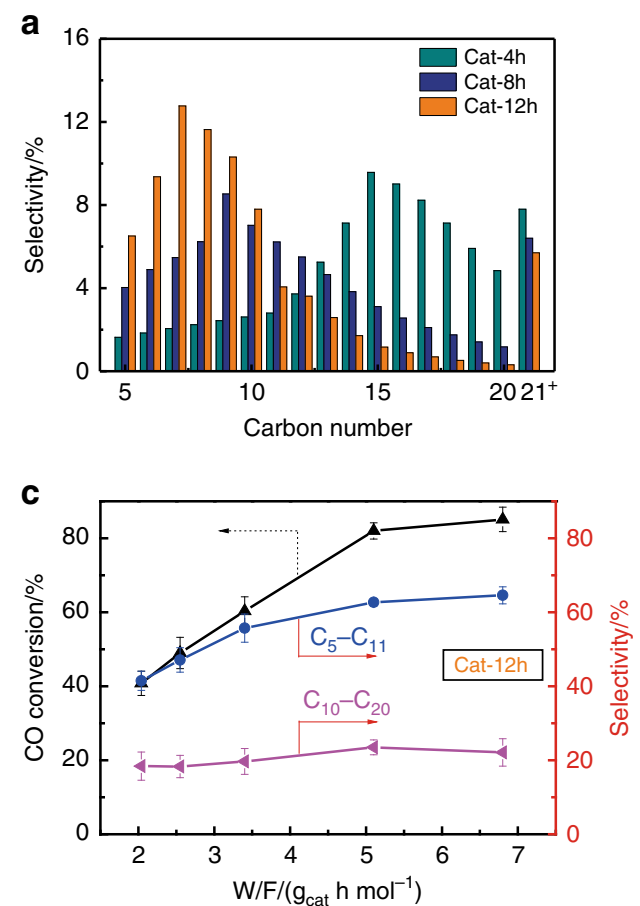
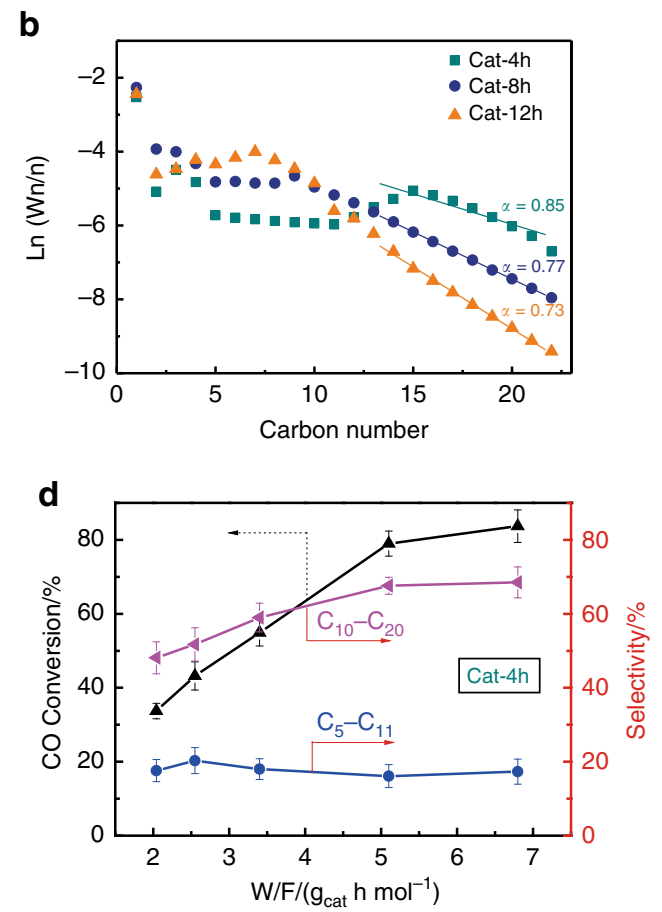

Fig. 5 FTS performance of the Cat-xh catalysts. a Distributions of the $\mathrm{C}_{5}{ }^{+}$products of the Cat-xh catalysts. $\mathbf{b}$ ASF distributions for the Cat-xh catalysts. Effect of contact time on activity and selectivity of $\mathbf{c}$ Cat-12h, and $\mathbf{d}$ Cat- $4 \mathrm{~h}$. Reaction conditions: $T=220^{\circ} \mathrm{C}, P=2 \mathrm{MPa}, \mathrm{W} / \mathrm{F}=2.0-6.8 \mathrm{~g}$ cat $\mathrm{h}$ mol ${ }^{-1}, \mathrm{CO} /$ $\mathrm{H}_{2}=1 / 2$. Error bars indicate s.d. $(n=5)$
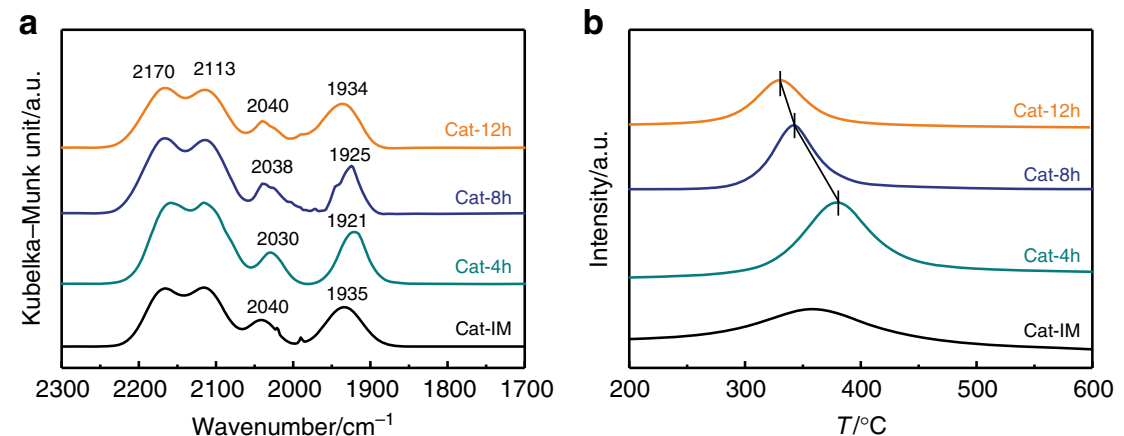

Fig. 6 Interaction between CO and the reduced catalysts. a In situ DRIFTS spectra of CO adsorption on the reduced catalysts. $\mathbf{b}$ CO-TPD/MS profiles of the reduced catalysts

programmed desorption and Fourier transform infrared spectroscopy of pyridine adsorption suggest that the acidic features of the Cat- $x$ h catalysts are very close. Therefore, the textural structures and acid properties of the Cat- $x$ h catalysts did not play a dominant role in determining the selectivity of the FTS products. Catalysts with different metal sizes will expose different surface sites, and a uniform crystallite size here will guarantee the reaction occurring on similar surface sites to produce specific products $^{26-29}$. Indeed, Kang et al. ${ }^{30}$ found that the uniform $\mathrm{Fe}_{5} \mathrm{C}_{2}$-based nanocatalysts presented the selectivity of $\sim 38 \%$ towards gasoline-range hydrocarbons. Similarly, our Cat-xh catalysts realize the specific product selectivity because of their uniform crystallite size distributions. Spatial confinement structures may affect accessibility of active sites to reaction intermediates, determining varied selectivities ${ }^{3,5,6,31}$. For example, the Cat-12h and Cat-IM catalysts have the similar number of the active sites (Table 1 ), but the $\mathrm{C}_{5}{ }^{+}$selectivity of the former $(80.0 \%)$ is higher than that of the latter $(67.3 \%)$ because of the confinement effect. The spatial confinement of the silica prevents the aggregation of the cobalt nanocrystals, and prolongs contact time of the trapped reaction intermediates with the active sites, inducing the growth of the long chain hydrocarbons, beyond the classic ASF model.

In order to further clarify the role of silica confinement, we synthesized additional two reference catalysts of Cat- $4 \mathrm{~h}-1$ and Cat4h-2 using the similar preparation method with the Cat-4h catalyst, except that the TEOS/Co molar ratios of the Cat-4h-1, Cat-4h, and Cat-4h-2 were 2, 4, and 8, respectively. Supplementary Fig. 11a-c displays the TEM images of the reduced catalysts. Increasing the TEOS/Co molar ratios will embed cobalt crystallites deeper into the silica bulk matrix ${ }^{32-34}$. Their FTS activity data based on the same cobalt content are given in Supplementary Table 7. Although the depth of the cobalt crystallites embedded into the silica is different, they exhibit the similar catalytic behavior (CO conversion and $\mathrm{C}_{5}{ }^{+}$ selectivity), and especially the high selectivity towards $C_{10}-C_{20}$ products. Probably, it is because that they have the same size of the cobalt crystallites, guaranteed by the confined structure, and thus exhibit the similar product distribution.

We conducted the experiments of in situ diffuse reflectance infrared Fourier transform spectroscopy (DRIFTS) with 
adsorption of $\mathrm{CO}$ to illuminate the nature of the active sites in the confined Cat- $x$ h catalysts. Figure 6a presents the in situ DRIFTS spectra of $\mathrm{CO}$ adsorbed at $30^{\circ} \mathrm{C}$ on the reduced catalysts. With the decrease of the crystallite sizes of cobalt in the Cat- $x \mathrm{~h}$ catalysts, the band of $\mathrm{CO}$ adsorbed in linear-type ${ }^{35,36}$ shifted from 2040 to $2030 \mathrm{~cm}^{-1}$, and the band of $\mathrm{CO}$ adsorbed in bridgetype ${ }^{37,38}$ also shifted from 1934 to $1921 \mathrm{~cm}^{-1}$. The red shift of the IR bands indicates the strengthened $\mathrm{Co}-\mathrm{C}$ bond ${ }^{39,40}$. In addition, we also conducted the experiments of in situ DRIFTS with adsorption of syngas at $220^{\circ} \mathrm{C}$. In Supplementary Fig. 12, only linearly adsorbed $\mathrm{CO}$ band located at $\sim 2055 \mathrm{~cm}^{-1}$ was observed $^{37}$. As the crystallite size of cobalt decreases, the IR band exhibits the red shift, indicating an enhanced electron backdonation from the metallic $d$ orbitals to the $\pi^{*}$ antibonding molecular orbital of CO. It is consistent with the result of DRIFTS with adsorption of $\mathrm{CO}$ at $30^{\circ} \mathrm{C}$. The smaller cobalt exposes more surface atoms with a lower coordination number, leading to an increased localization of the valence electrons. This localization causes an upward shift of the center of $d$-band, which will strengthen the bond between cobalt and adsorbate ${ }^{9}$.

In order to further understand the interaction between the adsorbed $\mathrm{CO}$ and the confined cobalt nanocrystals on the catalytic performance, we performed the CO-temperature programmed desorption/Mass spectroscopy (CO-TPD/MS) measurements over the reduced Cat- $x$ h catalysts (Fig. 6b). The catalysts show one desorption peak of $\mathrm{CO}$ in the range of $270-430^{\circ} \mathrm{C}$. The desorption quantity and desorption temperature of $\mathrm{CO}$ increased with the decrease of the crystallite sizes of cobalt. According to the literatures ${ }^{41,42}$, the desorbed $\mathrm{CO}$ is generated from the recombination of the $\mathrm{C}^{*}$ and $\mathrm{O}^{*}$ species adsorbed on the metal sites. The findings from CO-TPD/MS indicate that the smaller cobalt crystallites can more strongly adsorb the $\mathrm{C}^{\star}$ species compared with the larger ones, resulting in the higher desorption temperature. It coincides with the results of in situ DRIFTS in Fig. 6a and Supplementary Fig. 12. Among the Cat- $x$ h catalysts, the Cat- $4 \mathrm{~h}$ catalyst with the smallest cobalt crystallites possesses the lowest TOF value, because the strongest interaction between cobalt and adsorbate inhibits desorption of adsorbates therein. However, they present the similar apparent $\mathrm{CO}$ conversion (Table 2) because the Cat-4h catalyst with the smaller cobalt crystallites can expose more active sites, as listed in Table 1. Additionally, because of the high dispersion of cobalt, the large amount of the $\mathrm{C}^{\star}$ species exists on the Cat- $4 \mathrm{~h}$ catalyst.

The surface carbide mechanism ${ }^{43-45}$ is widely accepted to explain catalytic behaviors of FTS catalysts in Supplementary Fig. 13. In the carbide mechanism, direct $\mathrm{CO}$ dissociation occurs on the surface of active cobalt sites. The chemisorbed carbon $\left(\mathrm{C}^{*}\right)$ species undergo hydrogenation to form $\mathrm{CH}_{x}(1 \leq x \leq 3)$ groups, and subsequently the $\mathrm{CH}_{x}$ groups act as monomers and chain initiators for chain growth. It is worthy to note that the $\mathrm{CH}_{x}$ coverage must be high enough to boost up chain growth ${ }^{43,44}$. As discussed in Fig. 6, the small-sized cobalt nanocrystals expose the more active sites (Table 1), which will create more reaction intermediates inside the confinement space to prolong their contact time, favoring the chain growth and the high selectivity towards heavy hydrocarbons. It can well explain our findings as opposed to the view that larger Co metallic crystallites produce heavier hydrocarbons ${ }^{8,16,26,27}$. Therefore, the differences in FTS product distribution observed in the Cat-xh catalysts are likely caused by the two factors including the intrinsic characteristic related to the crystallite size of cobalt and the confinement structure of the catalysts.

Supplementary Fig. 14 shows the thermal gravimetric (TG) profiles of the spent catalysts. The weight loss below $150^{\circ} \mathrm{C}$ is attributed to removal of water, while that above $200^{\circ} \mathrm{C}$ is ascribed to combustion of heavy FTS products ${ }^{23}$. In Supplementary
Fig. 14, the heavier FTS products deposited on the surface of the spent Cat- $x \mathrm{~h}$ catalysts with the smaller cobalt size, which is in agreement with the results of the FTS activity. It provides further evidence that the $\alpha$ value increases with the decreased crystallite size of the confined cobalt catalyst (Fig. 5b). Thus, the Cat- $4 \mathrm{~h}$ catalyst has the high selectivity towards the diesel-range products.

Supplementary Fig. 15 compares the TEM images of the spent catalysts and the corresponding crystallite size distributions. The crystallite sizes of cobalt had little change before and after the FTS reactions for the Cat- $x$ h catalysts, but the cobalt species seriously aggregated on the Cat-IM catalysts. It indicates that the embedment of cobalt into silica can effectively inhibit its aggregation.

\section{Discussion}

It is demonstrated that the embedment of cobalt into mesoporous silica support, likely water-melon seeds inside pulps, is a promising strategy to precisely control the crystallite size of the cobalt based FTS catalysts. The spatial confinement can effectively inhibit the aggregation of the cobalt nanocrystals during the FTS reactions, which avoids misunderstandings caused by size change, concerning the function of the crystallite sizes of cobalt on the selectivity of the products. Moreover, the contact time between the trapped reaction intermediates and active sites can be prolonged inside the confined space, further boosting up the growth of long chain hydrocarbons. We reveal that the crystallite size of the confined cobalt catalysts can significantly affect the catalytic behaviors in FTS. With the enlarged cobalt crystallites $\left(d\left(\mathrm{Co}^{0}\right)_{\mathrm{T}}\right)$ from $7.2 \mathrm{~nm}$ of the Cat- $4 \mathrm{~h}$ to $11.4 \mathrm{~nm}$ of the Cat-12h, the TOF increased from $3.9 \times 10^{-2}$ to $6.4 \times 10^{-2} \mathrm{~s}^{-1}$, but the major product selectivity changed reversely from $66.2 \%$ of diesel-range hydrocarbons to $62.4 \%$ of gasoline-range hydrocarbons. Compared with the large size of cobalt, the small ones can strongly adsorb and capture the larger amount of the $\mathrm{C}^{\star}$ species, which guarantees the high enough $\mathrm{CH}_{x}$ coverage inside the confined space to stimulate chain growth by the carbide mechanism. Our results provide the new insights into the development of highly active and selective catalyst systems for the related industrial processes.

\section{Methods}

Synthesis of $\mathrm{Co}_{3} \mathrm{O}_{4}$ nanocrystal. Cobalt acetate of $1.17 \mathrm{~g}$ and TTAB of $4.26 \mathrm{~g}$ were added to a solution containing ethanol of $100 \mathrm{~mL}$ at $30^{\circ} \mathrm{C}$ under vigorous stirring. Ammonia solution was utilized to control the $\mathrm{pH}$ value of the solution $(\mathrm{pH}=8)$. Subsequently, the mixture was sealed in a $150 \mathrm{~mL}$ Teflon-lined autoclave and hydrothermally synthesized at $150^{\circ} \mathrm{C}$ for $x \mathrm{~h}(x=4,8,12)$ to obtain the TTABcapped $\mathrm{Co}_{3} \mathrm{O}_{4}$ nanocrystals. The corresponding $\mathrm{Co}_{3} \mathrm{O}_{4}$ nanocrystals were denoted as $\mathrm{Co}_{3} \mathrm{O}_{4}-x \mathrm{~h}(x=4,8,12)$

$\mathrm{Co}_{3} \mathrm{O}_{4}$ nanocrystals embedded into $\mathrm{SiO}_{2}$ supports. The suspension of the obtained TTAB-capped $\mathrm{Co}_{3} \mathrm{O}_{4}$ nanocrystals was added to ethanol of $185 \mathrm{~mL}$ and deionized water of $185 \mathrm{~mL}$ at $30^{\circ} \mathrm{C}$ under vigorous stirring. Then, TTAB solution of $5.58 \mathrm{~g}$ containing TEOS of $20 \mathrm{~mL}$ was slowly added drop by drop to the above suspension. The suspension was kept stirring and refluxing at $60^{\circ} \mathrm{C}$ for $15 \mathrm{~h}$ to form the $\mathrm{Co}_{3} \mathrm{O}_{4}$-TTAB- $\mathrm{SiO}_{2}$ nanocomposite.

Thermal treatment. The obtained nanocomposite was retrieved by centrifugation and dried at $110^{\circ} \mathrm{C}$ for $12 \mathrm{~h}$. Then, the powder was calcined in air by raising its temperature to $400^{\circ} \mathrm{C}$ with a ramping rate of $5^{\circ} \mathrm{C} \mathrm{min}$ mil $^{-1}$ and holding at $400{ }^{\circ} \mathrm{C}$ for $4 \mathrm{~h}$. The achieved catalyst was named as Cat- $x \mathrm{~h}(x=4,8,12)$, where ' $x \mathrm{~h}$ ' was the hydrothermal synthesis period of the $\mathrm{Co}_{3} \mathrm{O}_{4}$ nanocrystals.

Synthesis of catalysts with different cobalt loading. $\mathrm{Co}_{3} \mathrm{O}_{4}$ nanocrystals were synthesized by the same method using hydrothermal synthesis period of $4 \mathrm{~h}$, as mentioned above. The process of $\mathrm{Co}_{3} \mathrm{O}_{4}$ nanocrystals embedded into $\mathrm{SiO}_{2}$ supports was also similar to above described method, but the molar ratio of TEOS/Co was adjusted for controlling the embedment depth of cobalt crystallites. The TEOS/Co molar ratios of the Cat $-4 \mathrm{~h}-1$, Cat- $4 \mathrm{~h}$, and Cat- $4 \mathrm{~h}-2$ were 2,4 , and 8 , respectively. The final catalyst was obtained after drying and calcining under the same conditions. 
For the purpose of comparison, we prepared reference catalysts by impregnation of as-synthesized $\mathrm{Co}_{3} \mathrm{O}_{4}$-xh nanocrystals over silica supports, which were named as Cat-IM-xh. Here, 'IM' standed for impregnation method and ' $x$ h'standed for hydrothermal periods of $\mathrm{Co}_{3} \mathrm{O}_{4}$ nanocrystals. And the other reference catalyst of the Cat-IM, was prepared by a conventional incipient-wetness impregnation method. Briefly, cobalt acetate was impregnated on the silica support. The heat treatment conditions including drying and calcining were the same as previously described. The mass fraction of the cobalt in all the catalyst was $~ 15 \%$ as determined by the inductively coupled plasma-mass spectroscopy (ICP-MS; Agilent 7700x).

Transmission electron microscopy. TEM images were recorded on a JEM-2100F (JEOL Co.) microscope. The crystallite size distributions were calculated upon the measurement of 200 crystallites coming from several images taken at different positions on the TEM grid. The surface-averaged crystallite size was calculated from $d\left(\mathrm{Co}^{0}\right)_{\mathrm{T}}=\frac{\sum n_{i} d_{i}^{3}}{\sum n_{i} d_{i}^{2}}$ with the standard deviation of $\sigma=\sqrt{\frac{\sum n_{i} \cdot\left(d_{i}-d\left(\mathrm{Co}^{0}\right)_{\mathrm{T}}\right)^{2}}{\Sigma n_{i}}}$, where $n_{i}$ was the frequency of occurrence of each $d_{i} \operatorname{size}^{7,46}$.

X-ray diffraction. XRD patterns were obtained on a Philips X'Pert Pro diffractometer using monochromatized Co Ka radiation $(\lambda=1.78897 \AA)$, scanning $2 \theta$ from $20^{\circ}$ to $80^{\circ}$ with a scanning speed of $6^{\circ} \mathrm{min}^{-1}$ at $40 \mathrm{kV}$ and $40 \mathrm{~mA}$. Diffraction patterns were manually analyzed with the Joint Committee of Powder Diffraction Standard (JCPDS) card. The average crystallite size of the $\mathrm{Co}_{3} \mathrm{O}_{4}\left(d\left(\mathrm{Co}_{3} \mathrm{O}_{4}\right)_{\mathrm{X}}\right)$ was estimated from the Scherrer's equation applied to the most intense (311) diffraction $\left(2 \theta=43.1^{\circ}\right)$ using a shape factor $K=0.9^{47}$. The mean crystallite size of metallic cobalt $\left(d\left(\mathrm{Co}^{0}\right)_{\mathrm{X}}\right)$ was then obtained from the corresponding crystallite size of $\mathrm{Co}_{3} \mathrm{O}_{4}$ by applying the molar volume correction: $d\left(\mathrm{Co}^{0}\right)_{\mathrm{X}}=\frac{3}{4} d\left(\mathrm{Co}_{3} \mathrm{O}_{4}\right)_{\mathrm{X}}$.

X-ray absorption spectroscopy. X-ray absorption measurements were carried out at 14W1 beamline in Shanghai Synchrotron Radiation Facility (SSRF) and 1W1B beamline in Beijing Synchrotron Radiation Facility (BSRF). The X-ray Absorption Fine Structure (XAFS) data were collected in the transmission mode through a $\mathrm{Si}$ (111) double crystal monochromator. $\mathrm{Co}_{3} \mathrm{O}_{4}$ and $\mathrm{Co}$ foil were used as reference compounds for Extended X-ray Absorption Fine Structures (EXAFS) analysis. The ex-situ spectra of Co K-edge of the Cat- $x$ h catalysts and references were recorded at room temperature (RT) in transmission mode. For the collection of in situ XANES spectra at RT, a mixture gas composing of $10 \mathrm{vol} . \% \mathrm{H}_{2} / \mathrm{N}_{2}$ was introduced into the in situ sample chamber allowing heating to $400^{\circ} \mathrm{C}$ for $10 \mathrm{~h}$, and then the cell was cooled down to RT. We calibrated the monochromator by setting the first inflection point of the K-edge spectrum of the Co foil at $7709 \mathrm{eV}$.

Nitrogen adsorption measurements. The nitrogen adsorption-desorption isotherms were determined on a Quantachrome Quadrasorb SI apparatus at $-197^{\circ} \mathrm{C}$. The specific surface areas were obtained in a relative pressure range from 0.05 to 0.30 and were calculated using the Brunaue-Emmett-Teller (BET) method. The total pore volume was calculated from the amount of $\mathrm{N}_{2}$ vapor adsorbed at a relative pressure of 0.99

Chemical adsorption experiment. Temperature programmed reduction (TPR), $\mathrm{H}_{2}-\mathrm{O}_{2}$ titration and temperature programmed desorption (TPD) experiments were carried out with a TPDRO apparatus (TP-5080, Tianjin Xianquan Co., Ltd) equipped with a thermal conductivity detector (TCD). TPR measurement was performed in a flow of 8 vol. $\% \mathrm{H}_{2} / \mathrm{N}_{2}\left(30 \mathrm{~mL} \mathrm{~min}^{-1}\right)$ at a heating rate of $10^{\circ} \mathrm{C} \mathrm{min}$ ${ }^{-1}$ from RT to $900^{\circ} \mathrm{C}$.

The amounts of surface metal atoms of the cobalt catalysts were measured by $\mathrm{H}_{2}$-chemisorption experiments. The sample of $100 \mathrm{mg}$ was reduced at $400{ }^{\circ} \mathrm{C}$ for $10 \mathrm{~h}$ in $\mathrm{H}_{2}$ flow, and then evacuated at $400^{\circ} \mathrm{C}$ for $1 \mathrm{~h}$ in $\mathrm{N}_{2}$ flow prior to measurement of $\mathrm{H}_{2}$ titration at $100^{\circ} \mathrm{C}$. Dispersion percentage $(D \%)$ was calculated according to the equation $D \%=\frac{1.179 X}{W f}$, where $X$ was the total $\mathrm{H}_{2}$ uptake in micromoles per gram of catalyst, $W$ was the weight percentage of cobalt, and $f$ was the reduction degree calculated from $\mathrm{O}_{2}$-titration. Reduction degrees of the reduced catalysts were determined by $\mathrm{O}_{2}$-titration at $400{ }^{\circ} \mathrm{C}$ in a flow of helium. The reaction of the metallic cobalt species with oxygen was considered to form $\mathrm{Co}_{3} \mathrm{O}_{4}$. The particle sizes of cobalt $\left(d\left(\mathrm{Co}^{0}\right)_{\mathrm{H}}\right)$, were estimated from the total amount of chemisorbed $\mathrm{H}_{2}$, assuming an atomic ratio of $\mathrm{H} / \mathrm{Co}=1$, and a hemispherical crystallite geometry with a surface atomic density of 14.6 atoms $\mathrm{nm}^{-2}$. Thus, $d\left(\mathrm{Co}^{0}\right)_{\mathrm{H}}=\frac{96}{D \%}$.

CO-TPD/MS experiments were carried out to study the interaction between cobalt crystallite surfaces and carbon monoxide. The sample of $100 \mathrm{mg}$ was reduced at $400{ }^{\circ} \mathrm{C}$ for $10 \mathrm{~h}$ in $\mathrm{H}_{2}$ flow in a quartz reactor, and then evacuated at 400 ${ }^{\circ} \mathrm{C}$ for $1 \mathrm{~h}$ in He flow prior to measurement of $\mathrm{CO}$ adsorption at RT. The sample was purged by He flow $\left(30 \mathrm{~mL} \mathrm{~min}^{-1}\right)$ at $\mathrm{RT}$ for $1 \mathrm{~h}$, and then was heated from RT to $800^{\circ} \mathrm{C}\left(10^{\circ} \mathrm{C} \mathrm{min}^{-1}\right)$. The signal of $\mathrm{CO} \mathrm{m} / \mathrm{z}=28$ was monitored with MS (HPR-20 QIC, Hiden Analytical Ltd.).

In situ X-ray photoelectron spectroscopy. In situ XPS spectra were recorded on a PHI 5000 Versa Probe with an aluminum anode ( $\mathrm{Al} \mathrm{Ka}=1486.6 \mathrm{eV})$ operating at
$25 \mathrm{~W}$. In the case of pretreated sample, the as-prepared catalysts were placed in the introduction chamber (IC), and then were transferred to the reaction chamber (RC) by a transfer rod. After degassing the RC, the samples were reduced by $\mathrm{H}_{2}$ at $400{ }^{\circ} \mathrm{C}$. As the temperature was cooled down from $400^{\circ} \mathrm{C}$ to RT, the samples were transferred back to IC, and were degassed again to remove the adsorbed $\mathrm{H}_{2}$. Subsequently, the samples were transferred to the main chamber (MC) for XPS detection with an accuracy of $\pm 0.1 \mathrm{eV}$.

In situ infrared spectroscopy. In situ diffuse reflectance infrared Fourier transform spectroscopy (DRIFTS) spectra were collected on a Nexus FT-IR spectrometer equipped with a MCT detector at the liquid nitrogen temperature and a diffuse reflectance attachment in the range of $650-4000 \mathrm{~cm}^{-1}$. The sample $(30-40$ $\mathrm{mg}$ ) was placed in an infrared cell with a $\mathrm{ZnSe}$ window and reduced for $10 \mathrm{~h}$ at atmospheric pressure in a hydrogen stream at $400{ }^{\circ} \mathrm{C}$. Subsequently, the system was cooled down to RT or $220^{\circ} \mathrm{C}$, and the background spectra were recorded. After introduction of carbon monoxide or syngas for $0.5 \mathrm{~h}$, the catalyst was purged with helium at RT or hydrogen at $220^{\circ} \mathrm{C}$ for $0.5 \mathrm{~h}$. All spectra were recorded with a resolution of $2 \mathrm{~cm}^{-1}$ and accumulation of 32 scans.

Catalytic tests. The FTS tests were carried out in a stainless steel fixed-bed reacto (i.d. $8 \mathrm{~mm}$ ) with a catalyst loading of $0.5 \mathrm{~g}$ (pellet size: $0.25-0.42 \mathrm{~mm}$ ). Prior to reaction, the catalysts were reduced in pure hydrogen at $400{ }^{\circ} \mathrm{C}$ for $10 \mathrm{~h}$. After the reduction, unless otherwise specified, the catalytic tests were carried out at $220^{\circ} \mathrm{C}$ and $2 \mathrm{MPa}$ in syngas $\left(\mathrm{CO} / \mathrm{H}_{2}=1 / 2, \mathrm{~W} / \mathrm{F}=5.1 \mathrm{gcat}_{\mathrm{cat}} \mathrm{h} \mathrm{mol}^{-1}\right)$. The reaction pressure was maintained by a back-pressure regulator. The thermocouple directly contacted the catalyst bed, and by moving thermocouples, we checked that no heat spot was detected during the FT reactions. Additionally, besides syngas, the feeding gas contained 1.5 vol.\% nitrogen, which was used as an internal standard for calculating the carbon monoxide conversion. To avoid possible condensation of the reaction products, the temperature of the whole pipelines from reactor to gas chromatography (GC) for product analysis was kept at $220^{\circ} \mathrm{C}$ during the catalytic tests. Gaseous reaction products were analyzed on-line by GC. Hydrocarbons were separated on a HP-PONA capillary column of GC and analyzed with a flameionization detector (FID). The analysis of $\mathrm{H}_{2}, \mathrm{~N}_{2}, \mathrm{CO}, \mathrm{CH}_{4}$, and $\mathrm{CO}_{2}$ was performed with a TDX-01 packed column of GC and a TCD. The analysis of lighter paraffins and olefins $\left(\mathrm{C}_{1}-\mathrm{C}_{5}\right)$ was carried out with an HP-PLOT/Q capillary column of GC. CO conversion (\%) and product selectivity (\%) were defined in supplementary information. Carbon balances were better than $90 \%$ for all of the tests in this work. The chain growth probability $(\alpha)$ was evaluated from the slope of straight lines using $\mathrm{C}_{14}-\mathrm{C}_{21}$ products determined by equation

$W n=n \cdot \alpha^{n-1} \cdot(1-\alpha)^{2}$. All the catalytic results of the catalysts were obtained after no less than $20 \mathrm{~h}$ on stream.

Data availability. The data that support the findings of this work are available within the article and its Supplementary Information files. All other relevant data supporting the findings of this study are available from the corresponding author on reasonable request.

Received: 6 February 2018 Accepted: 24 July 2018

Published online: 14 August 2018

\section{References}

1. Regalbuto, J. R. Cellulosic biofuels-got gasoline? Science 325, 822-824 (2009).

2. Jiao, F. et al. Selective conversion of syngas to light olefins. Science 351, 1065-1068 (2016).

3. Chen, W., Fan, Z. L., Pan, X. L. \& Bao, X. H. Effect of confinement in carbon nanotubes on the activity of Fischer-Tropsch iron catalyst. J. Am. Chem. Soc. 130, 9414-9419 (2008).

4. Peng, X. et al. Impact of hydrogenolysis on the selectivity of the FischerTropsch synthesis: Diesel fuel production over mesoporous zeolite-Ysupported cobalt nanoparticles. Angew. Chem. Int. Ed. 127, 4636-4639 (2015).

5. Yu, G. et al. $\mathrm{Fe}_{\mathrm{x}} \mathrm{O}_{\mathrm{y}} @ \mathrm{C}$ spheres as an excellent catalyst for Fischer-Tropsch synthesis. J. Am. Chem. Soc. 132, 935-937 (2009).

6. Subramanian, V. et al. Nanoreactors: an efficient tool to control the chainlength distribution in Fischer-Tropsch synthesis. ACS Catal. 6, 1785-1792 (2016).

7. Prieto, G., Martínez, A., Concepción, P. \& Moreno-Tost, R. Cobalt particle size effects in Fischer-Tropsch synthesis: Structural and in situ spectroscopic characterisation on reverse micelle-synthesised Co/ITQ-2 model catalysts. J. Catal. 266, 129-144 (2009).

8. Bezemer, G. L. et al. Cobalt particle size effects in the Fischer-Tropsch reaction studied with carbon nanofiber supported catalysts. J. Am. Chem. Soc. 128, 3956-3964 (2006).

9. Den Breejen, J. P. et al. On the origin of the cobalt particle size effects in Fischer-Tropsch catalysis. J. Am. Chem. Soc. 131, 7197-7203 (2009). 
10. Borg, $\varnothing$. et al. Fischer-Tropsch synthesis: cobalt particle size and support effects on intrinsic activity and product distribution. J. Catal. 259, 161-164 (2008).

11. Rane, S., Borg, Ø., Rytter, E. \& Holmen, A. Relation between hydrocarbon selectivity and cobalt particle size for alumina supported cobalt FischerTropsch catalysts. Appl. Catal. A 437, 10-17 (2012).

12. Iglesia, E. Design, synthesis, and use of cobalt-based Fischer-Tropsch synthesis catalysts. Appl. Catal. A 161, 59-78 (1997).

13. D'souza, L., Regalbuto, J. R. \& Miller, J. T. Preparation of carbon supported cobalt by electrostatic adsorption of $\left[\mathrm{Co}\left(\mathrm{NH}_{3}\right)_{6}\right] \mathrm{Cl}_{3}$. J. Catal. 254, 157-169 (2008).

14. Bezemer, G. L. et al. Preparation of Fischer-Tropsch cobalt catalysts supported on carbon nanofibers and silica using homogeneous deposition-precipitation. J. Catal. 237, 291-302 (2006).

15. Joo, S. H. et al. Thermally stable Pt/mesoporous silica core-shell nanocatalysts for high-temperature reactions. Nat. Mater. 8, 126-31 (2009).

16. Xiong, H. F., Zhang, Y. H., Liew, K. Y. \& Li, J. L. Fischer-Tropsch synthesis: the role of pore size for Co/SBA-15 catalysts. J. Mol. Catal. A 295, 68-76 (2008).

17. Ward, M. R., Boyes, E. D. \& Gai, P. L. In situ aberration-corrected environmental TEM: Reduction of model $\mathrm{Co}_{3} \mathrm{O}_{4}$ in $\mathrm{H}_{2}$ at the atomic level. ChemCatChem 5, 2655-2661 (2013).

18. Sun, X. H. et al. Manufacture of highly loaded silica-supported cobalt FischerTropsch catalysts from a metal organic framework. Nat. Commun. 8 , 1680-1688 (2017).

19. Graham, U. M. et al. Fischer-Tropsch synthesis: higher oxygenate selectivity of cobalt catalysts supported on hydrothermal carbons. ACS Catal. 4, 1662-1672 (2014).

20. Borg, $\varnothing$. et al. Fischer-Tropsch synthesis over $\gamma$-alumina-supported cobalt catalysts: effect of support variables. J. Catal. 248, 89-100 (2007)

21. Zhang, Y., Shinoda, M. \& Tsubaki, N. Development of bimodal cobalt catalysts for Fischer-Tropsch synthesis. Catal. Today 93, 55-63 (2004).

22. Sun, Z. et al. A general chelate-assisted co-assembly to metallic nanoparticlesincorporated ordered mesoporous carbon catalysts for Fischer-Tropsch synthesis. J. Am. Chem. Soc. 134, 17653-17660 (2012).

23. Li, X., He, J., Meng, M., Yoneyama, Y. \& Tsubaki, N. One-step synthesis of H$\beta$ zeolite-enwrapped $\mathrm{Co} / \mathrm{Al}_{2} \mathrm{O}_{3}$ Fischer-Tropsch catalyst with high spatial selectivity. J. Catal. 265, 26-34 (2009).

24. Kang, J. et al. Mesoporous zeolite-supported ruthenium nanoparticles as highly selective Fischer-Tropsch catalysts for the production of $\mathrm{C}_{5}-\mathrm{C}_{11}$ isoparaffins. Angew. Chem. Int. Ed. 123, 5306-5309 (2011).

25. Sartipi, S., Parashar, K., Makkee, M., Gascon, J. \& Kapteijn, F. Breaking the Fischer-Tropsch synthesis selectivity: Direct conversion of syngas to gasoline over hierarchical Co/H-ZSM-5 catalysts. Catal. Sci. Technol. 3, 572-575 (2013).

26. Zhang, Q., Cheng, K., Kang, J., Deng, W. \& Wang, Y. Fischer-Tropsch catalysts for the production of hydrocarbon fuels with high selectivity. ChemSusChem 7, 1251-1264 (2014).

27. Fischer, N., Van Steen, E. \& Claeys, M. Structure sensitivity of the FischerTropsch activity and selectivity on alumina supported cobalt catalysts. J. Catal. 299, 67-80 (2013).

28. Van Helden, P., Ciobîcă, I. M. \& Coetzer, R. L. The size-dependent site composition of FCC cobalt nanocrystals. Catal. Today 261, 48-59 (2016).

29. Nijs, H. H. \& Jacobs, P. A. Metal particle size distribution and Fischer-Tropsch selectivity. an extended Schulz-Flory model. J. Catal. 65, 328-334 (1980).

30. Kang, S. et al. High-performance $\mathrm{Fe}_{5} \mathrm{C}_{2} @ \mathrm{CMK}-3$ nanocatalyst for selective and high-yield production of gasoline-range hydrocarbons. J. Catal. 349, 66-74 (2017)

31. Castillejos, E. et al. An efficient strategy to drive nanoparticles into carbon nanotubes and the remarkable effect of confinement on their catalytic performance. Angew. Chem. Int. Ed. 48, 2529-2533 (2009).

32. Niu, D. C., Ma, Z., Li, Y. S. \& Shi, J. L. Synthesis of core shell structured dualmesoporous silica spheres with tunable pore size and controllable shell thickness. J. Am. Chem. Soc. 132, 15144-15147 (2010).

33. Ding, H. L. et al. $\mathrm{Fe}_{3} \mathrm{O}_{4} @ \mathrm{SiO}_{2}$ core/shell nanoparticles: the silica coating regulations with a single core for different core sizes and shell thicknesses. Chem. Mater. 24, 4572-4580 (2012).

34. Jiao, Y. F. et al. Synthesis of discrete and dispersible hollow mesoporous silica nanoparticles with tailored shell thickness for controlled drug release. J. Mater. Chem. 22, 17636-17643 (2012).

35. Pang, S. H., Schoenbaum, C. A., Schwartz, D. K. \& Medlin, J. W. Directing reaction pathways by catalyst active-site selection using self-assembled monolayers. Nat. Commun. 4, 1-6 (2013).

36. Gaudet, J. R., de la Riva, A., Peterson, E. J., Bolin, T. \& Datye, A. K. Improved low-temperature $\mathrm{CO}$ oxidation performance of Pd supported on La-stabilized alumina. ACS Catal. 3, 846-855 (2013).
37. Sartipi, S. et al. Hierarchical H-ZSM-5-supported cobalt for the direct synthesis of gasoline-range hydrocarbons from syngas: Advantages, limitations, and mechanistic insight. J. Catal. 305, 179-190 (2013).

38. Matsubu, J. C., Yang, V. N. \& Christopher, P. Isolated metal active site concentration and stability control catalytic $\mathrm{CO}_{2}$ reduction selectivity. J. Am. Chem. Soc. 137, 3076-3084 (2015).

39. Tuxen, A. et al. Size-dependent dissociation of carbon monoxide on cobalt nanoparticles. J. Am. Chem. Soc. 135, 2273-2278 (2013).

40. Paredes-Nunez, A. et al. Nature and reactivity of the surface species observed over a supported cobalt catalyst under $\mathrm{CO} / \mathrm{H}_{2}$ mixtures. Catal. Today 242, 178-183 (2015).

41. Pauls, C., Przyrembel, D. \& Christmann, K. Dissociation of carbon monoxide on the rhenium (10-10) surface. J. Phys. Chem. B 108, 14749-14758 (2004).

42. Galhenage, R. P., Yan, H., Ahsen, A. S., Ozturk, O. \& Chen, D. A Understanding the growth and chemical activity of Co-Pt bimetallic clusters on $\mathrm{TiO}_{2}$ (110): $\mathrm{CO}$ adsorption and methanol reaction. J. Phys. Chem. C. 118, 17773-17786 (2014).

43. Rofer-DePoorter, C. K. A comprehensive mechanism for the Fischer-Tropsch synthesis. Chem. Rev. 81, 447-474 (1981).

44. Ojeda, M. et al. CO activation pathways and the mechanism of FischerTropsch synthesis. J. Catal. 272, 287-297 (2010).

45. Gaube, J. \& Klein, H. F. Studies on the reaction mechanism of the FischerTropsch synthesis on iron and cobalt. J. Mol. Catal. A 283, 60-68 (2008).

46. Shi, L. et al. Surface impregnation combustion method to prepare nanostructured metallic catalysts without further reduction: As-burnt $\mathrm{Co} / \mathrm{SiO}_{2}$ catalysts for Fischer-Tropsch synthesis. ACS Catal. 1, 1225-1233 (2011).

47. Schanke, D. et al. Study of Pt-promoted cobalt CO hydrogenation catalysts. J. Catal. 156, 85-95 (1995).

\section{Acknowledgements}

This work is financially supported by National Natural Science Foundation of China (No 21676182, 21476159), the 973 program (2014CB932403), and the Program for Introducing Talents of Discipline to Universities of China (No.B06006). Y.T. thanks the financial aid for one-year stay in University of Toyama, Japan. N.T. thanks Japan Science and Technology Agency (JST) for CREST project (Grant Number 17-141003297). Financial aid from JST-SATREPS project is greatly appreciated.

\section{Author contributions}

X.G.L., Q.P.C., and Y.T. conceived, coordinated the research, and designed the experiments. Q.P.C., S.S.L., N.Z., K.M., and T.D. synthesized and characterized the catalysts, Z. J., L.H.W., J.Z., and L.R.Z. performed synchrotron experiments, F.G. and L.D. performed the XPS characterization and analyzed the results, X.G.L., Q.P.C., Y.T. and N.T. analyzed the experimental data, X.G.L., Q.P.C. and N.T. wrote the manuscript. X.G.L. supervised the whole project. All the authors participated in discussions of the research.

\section{Additional information}

Supplementary Information accompanies this paper at https://doi.org/10.1038/s41467018-05755-8.

Competing interests: The authors declare no competing interests.

Reprints and permission information is available online at http://npg.nature.com/ reprintsandpermissions/

Publisher's note: Springer Nature remains neutral with regard to jurisdictional claims in published maps and institutional affiliations.

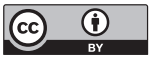

Open Access This article is licensed under a Creative Commons Attribution 4.0 International License, which permits use, sharing, adaptation, distribution and reproduction in any medium or format, as long as you give appropriate credit to the original author(s) and the source, provide a link to the Creative Commons license, and indicate if changes were made. The images or other third party material in this article are included in the article's Creative Commons license, unless indicated otherwise in a credit line to the material. If material is not included in the article's Creative Commons license and your intended use is not permitted by statutory regulation or exceeds the permitted use, you will need to obtain permission directly from the copyright holder. To view a copy of this license, visit http://creativecommons.org/ licenses/by/4.0/.

(C) The Author(s) 2018 